\title{
Phage selection of cyclic peptide antagonists with increased stability toward intestinal proteases
}

\author{
Vanessa Baeriswyl and Christian Heinis ${ }^{1}$ \\ Institute of Chemical Sciences and Engineering, Ecole Polytechnique \\ Fédérale de Lausanne (EPFL), Lausanne CH-1015, Switzerland \\ ${ }^{1}$ To whom correspondence should be addressed. \\ E-mail: christian.heinis@epfl.ch
}

Received June 1, 2012; revised September 6, 2012; accepted September 29, 2012

\section{Edited by Laurent Jespers}

The oral delivery of protein and peptide drugs is limited by their proteolytic degradation and the poor absorption across the intestinal epithelia. In this work, we exposed a phage library of small bicyclic peptides $(<1.5 \mathrm{kDa})$ to a pancreatic extract of proteases prior to affinity selection to enrich binders with higher stability in the intestinal environment. Panning with the therapeutic target plasma kallikrein yielded potent inhibitors $\left(K_{\mathrm{i}} \mathrm{s}\right.$ between 5.6 and $336 \mathrm{nM}$ ) wherein bicyclic peptides isolated with proteolytic pressure were more stable. A proline residue found in a specific position of several resistant bicyclic peptides proved to be a 'protective mark', rendering the bicyclic peptides resistant to significantly higher concentrations of intestinal proteases while retaining essentially their inhibitory activity.

Keywords: bicyclic peptide/phage display/plasma kallikrein/ proteolytic phage display/proteolytic stability

\section{Introduction}

Protein and peptide therapeutics have excellent properties such as high potency and selectivity but generally require parenteral application which is not convenient, particularly in the treatment of chronic diseases. The oral delivery of therapeutic peptide and protein drugs has ever since been a challenge as the digestive tract does not differentiate between therapeutic and non-therapeutic polypeptides and therefore protein and peptide drugs are digested as the food protein are (Mahato et al., 2003). As a result of this proteolytic degradation and the poor absorption across the intestinal epithelia, the oral bioavailability of most protein and peptide drugs is significantly $<1 \%$ (Zhou and Li Wan Po, 1991). Toward the generation of orally available biologics, a number of engineering and formulation strategies have been applied, of which some have led to the establishment of oral peptide treatments (Morishita and Peppas, 2006; Antosova et al., 2009).

One step toward the development of more orally available protein and peptide drugs consists in increasing the proteolytic stability of this class of therapeutics. Various approaches have been used to achieve this goal including chemical modification of peptide termini, replacement of amino acid side chains or amide bonds, inversion of configurations and peptide cyclization (Zhou and Li Wan Po, 1991). Recently, a highly stable thrombin inhibitor was engineered by inserting a binding region into a proteolytically stable knottin scaffold (Getz et al., 2011). Formulation excipients containing enzyme inhibitors or $\mathrm{pH}$-lowering buffer, both leading to digestive enzyme inactivation, have been developed (Morishita and Peppas, 2006). Coating of the protein or peptide drug using various polymers, liposomes or nanoparticles also contributed to increased resistance to proteolytic degradation (Morishita and Peppas, 2006). For example, coating insulin with amphiphilic oligomers, protecting this drug from the action of digestive enzymes as well as facilitating its absorption through the intestinal epithelia, increased its oral bioavailability up to 5\% (Kipnes et al., 2003; Morishita et al., 2006). Considering the typically high potencies of protein and peptide drugs, a bioavailability even below $1 \%$ may be sufficient to achieve therapeutic effects.

Here, we aimed at developing bicyclic peptide inhibitors of human plasma kallikrein (hPK) with high stability in the intestinal environment for potential oral application. An inhibitor of hPK based on the Kunitz domain has been approved in 2009 for the treatment of hereditary angioedema, a life-threatening disease characterized by recurrent episodes of severe swelling (angioedema) (Stolz and Horn, 2010). Due to its large size and proteinous nature, the inhibitor requires administration by injection. Smaller, peptidic inhibitors based on bicyclic peptides were recently isolated from combinatorial libraries of bicyclic peptides and inhibit the plasma protease with low- to sub-nanomolar affinities (Heinis et al., 2009; Baeriswyl et al., 2012). Proteolytic stability measurements showed that the bicyclic peptides are significantly more stable than linear peptides with identical amino acid sequences (unpublished data). However, despite their comparatively high proteolytic stability, we estimated that the bicyclic inhibitors would not be sufficiently resistant to the high protease activities in the intestinal environment without excipients such as high concentrations of protease inhibitors. The well-characterized bicyclic peptide inhibitor of hPK inhibitor, PK15, has furthermore the handicap of being cleaved by hPK between Arg7 and Asn8 upon binding to the protease (Heinis et al., 2009). It is likely that the first peptide ring of PK15 binds to hPK similar as a substrate according to the so-called standard mechanism (Laskowski and Qasim, 2000). Since pancreatic serine proteases such as trypsin and chymotrypsin share high-sequence similarity with hPK, PK15 (and other peptidic inhibitors binding according to the standard mechanisms) might therefore have a particularly high risk of being cleaved by the pancreatic proteases.

Phage display technology combined with proteolytic pressure has been applied to evolve proteins or peptides with improved thermal and/or proteolytic stability. Kristensen and Winter (1998) and independently Sieber et al. (1998) inserted polypeptides between two domains of the minor coat protein 
p3 of filamentous phage to link protein stability with phage infectivity. They showed that phage with less-stable proteins were cleaved by proteases and lost their infectivity, while phage containing stable, folded guest proteins were propagated. This or similar proteolytic phage selection systems (Finucane et al., 1999) were used to evolve the stability of proteins such as RNase T1 (Sieber et al., 1998), barnase (Pedersen et al., 2002) and RNase S (Chakravarty et al., 2000 ) or to isolate folded protein domains from combinatorially shuffled polypeptide segments (Riechmann and Winter, 2000; Fischer et al., 2004; Riechmann and Winter, 2006).

In this work, we combined phage affinity selection and proteolytic selection to develop bicyclic peptides with improved stability toward intestinal proteases. We first assessed the stability of filamentous phage toward pancreatin, a mixture of the pancreatic digestive proteases found in the intestinal lumen. Subsequently, we combined treatment of bicyclic peptide phage libraries with pancreatin and affinity selections with hPK and characterized the inhibitory activity and proteolytic stability of isolated bicyclic peptides.

\section{Results}

\section{Stability of bicyclic peptides toward intestinal proteases}

The proteolytic stability of a previously generated bicyclic peptide hPK inhibitor, PK15, was assessed by incubation with different concentrations of pancreatin for $30 \mathrm{~min}$ at $37^{\circ} \mathrm{C}$ and subsequent analysis by reversed phase highperformance liquid chromatography (HPLC). Pancreatin is an extract of porcine pancreatic glands and the main component of the simulated intestinal fluid described in the US Pharmacopedia (www.usp.org). The extract contains digestive enzymes that are secreted into the lumen of the small intestine for protein breakdown. More than 50\% of PK15 was cleaved at pancreatin concentrations of $2.4 \mu \mathrm{g} / \mathrm{ml}$ (Fig. 1A). At $10 \mu \mathrm{g} / \mathrm{ml}$ pancreatin, $90 \%$ of the inhibitor was digested and at $20 \mu \mathrm{g} / \mathrm{ml}$ pancreatin or higher concentrations, $100 \%$ PK15 was inactivated (Fig. 1A). Mass spectrometric analysis of digested PK15 showed two degradation products with masses that corresponded to bicyclic peptides in which Phe6 or the dipeptide Phe6-Arg7, respectively, were dissected following the cleavage of two amide bonds (Supplementary Fig. S1). The cleavage sites are typical substrates of trypsin (C-terminally to Arg5 and Arg7) and chymotrypsin (C-terminally to Phe6) which are present in pancreatin at high concentrations. For the generation of bicyclic peptide inhibitors of hPK being more protease resistant than PK15, we estimated that phage should be exposed to pancreatin concentrations of $5 \mu \mathrm{g} / \mathrm{ml}$ or higher for $30 \mathrm{~min}$ at $37^{\circ} \mathrm{C}$.

\section{Assessment of the stability of phage toward intestinal proteases}

Filamentous phage previously proofed resistant to high protease concentrations (Kristensen and Winter, 1998; Sieber et al., 1998) but their resistance to the specific mixture of digestive enzymes in pancreatin has not been assessed. As a measure of the proteolytic resistance we determined the number of phage able to infect bacteria after incubation with different pancreatin concentrations. Wild-type phage remained infective even at the highest pancreatin concentration tested $(5 \mathrm{mg} / \mathrm{ml}$; Fig. 1B). For phage selection of bicyclic peptides, we preferred to use a phage mutant with a disulfide-free p3, (Kather et al., 2005) to prevent potential interference of the $\mathrm{p} 3$ cysteines with the cyclization reaction involving the thiol-reactive tris-(bromomethyl)benzene (TBMB). This phage mutant was less protease resistant but remained infectious at pancreatin concentrations as high as $20 \mu \mathrm{g} / \mathrm{ml}$ (Fig. 1B). Since PK15 is slightly more susceptible to pancreatin treatment, proteolytic phage selections were feasible and we estimated suitable concentrations of pancreatin to be between 5 and $20 \mu \mathrm{g} / \mathrm{ml}$. The infectivity of bicyclic peptide phage libraries was reduced at a similar extent as the one of monoclonal disulfide-free phage not displaying a peptide.

\section{Phage selections}

Phage affinity selections were combined with proteolytic selections. Since bicyclic peptides with a smaller molecular weight should have a better chance to cross the intestinal
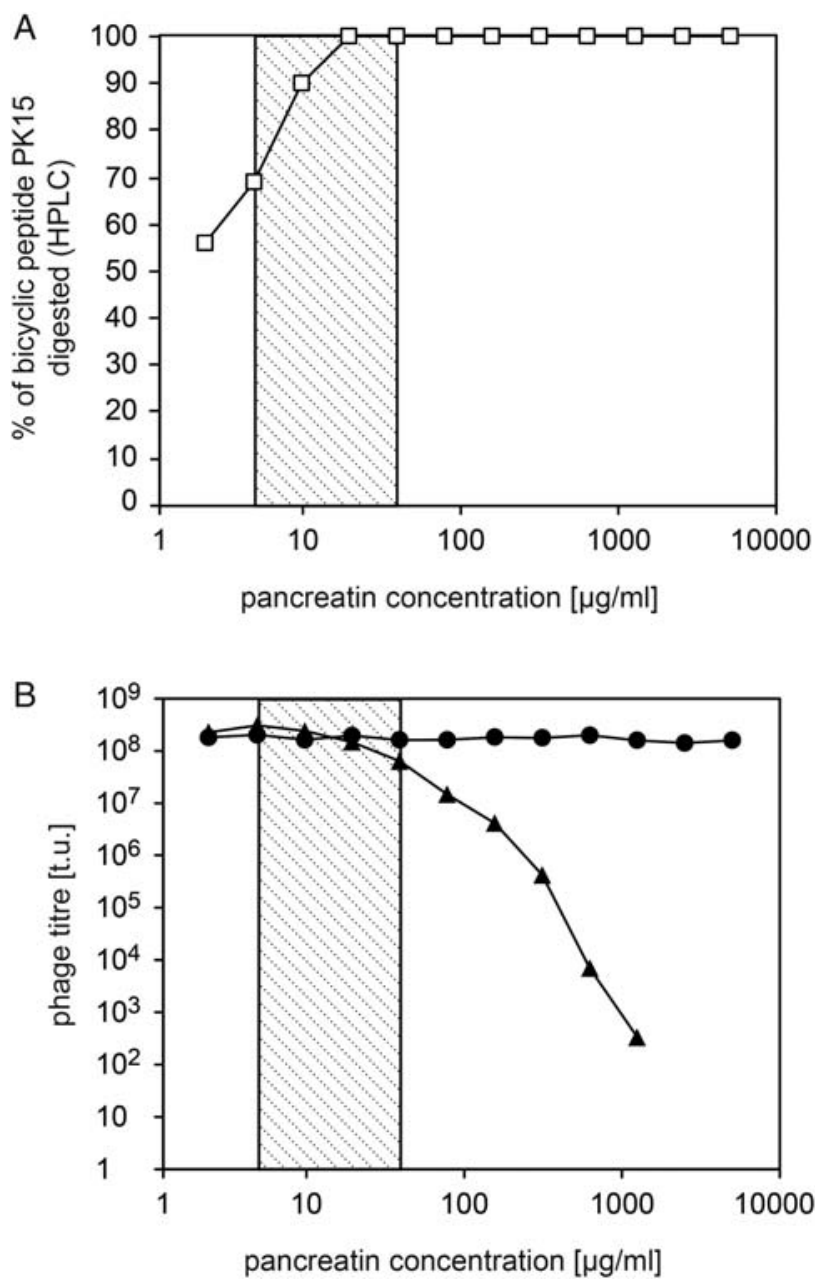

Fig. I. Effect of pancreatin activity on bicyclic peptide (A) and filamentous phage (B). A window of pancreatin concentrations suited for proteolytic phage display was assessed. The previously developed hPK bicyclic inhibitor PK15 (open square) and filamentous phage (wild-type fd phage (closed circle) and fd phage with cysteine-free p3 (Kather, Bippes and Schmid, 2005) (closed triangle); $2 \times 10^{8}$ t.u.) were incubated for $30 \mathrm{~min}$ at $37^{\circ} \mathrm{C}$ with various concentrations of pancreatin. The percentage of digested PK15 was assessed by HPLC. The number of functional phage was determined by measuring the infectivity. The hatched window indicates pancreatin concentration suitable for proteolytic phage selection using the disulfide-free phage $(5-40 \mu \mathrm{g} / \mathrm{ml})$. 
epithelium, we were particularly interested in improving the proteolytic stability of those. Two phage libraries with bicyclic peptides containing two rings of either three or four random amino acids (library $3 \times 3$ and library $4 \times 4$ ) were used (Fig. 2A). The libraries comprising $5.6 \times 10^{8}$ and $7.3 \times 10^{8}$ different peptide sequences, respectively, were produced by chemically cyclizing linear peptides on phage with TBMB as described before (Heinis et al., 2009). The two libraries were joined and subjected to a first affinity selection with hPK Isolated phage were amplified and, prior to the second round of affinity selection, treated for $30 \mathrm{~min}$ at $37^{\circ} \mathrm{C}$ with $0 \mu \mathrm{g} / \mathrm{ml}$ (control condition), 5, 10 or $20 \mu \mathrm{g} / \mathrm{ml}$ pancreatin. Titration of isolated phage showed that fewer phage were captured when treated with higher pancreatin concentrations $\left(8.2 \times 10^{6}\right.$, $8.3 \times 10^{2}, 1.9 \times 10^{2}$ and 10 phage at $0,5,10$ and $20 \mu \mathrm{g} / \mathrm{ml}$ pancreatin). Sequencing of isolated peptides after two rounds of phage panning performed without proteolytic pressure revealed that the binders predominantly derived from the $3 \times 3$ library (28 out of the 29 sequenced clones) although comparable numbers of phage from the $3 \times 3$ and $4 \times 4$ libraries were subjected to the selection (Fig. 2B). The peptides showed a clear consensus sequence with an aromatic amino acid in position 3, arginine in position 7 and valine or alanine in position $8\left(\mathrm{XC}^{\mathrm{F}} / \mathrm{WXXCR}_{\mathrm{W}}^{\mathrm{A}} / \mathrm{V} \mathrm{XXX}\right.$; Fig. $\left.2 \mathrm{~B}\right)$. When proteolytic pressure was applied prior to the second round of phage panning, this consensus sequence was also predominantly found wherein the fraction of clones derived from the $4 \times 4$ library had increased (14 out of the 65 sequenced clones; Fig. 2B).

\section{Inhibitory activity and proteolytic stability of isolated bicyclic peptides}

Peptides of four clones isolated without and five with proteolytic pressure (10 or $20 \mu \mathrm{g} / \mathrm{ml}$ pancreatin) were chemically synthesized with a free $\mathrm{N}$-terminus and an amidated C-terminus, cyclized with TBMB and their inhibitory activity determined. The bicyclic peptides inhibited hPK with $\mathrm{IC}_{50} \mathrm{~S}$ ranging from 7.5 to $450 \mathrm{nM}$ (Fig. 2B, Table I). In inhibitory assays, performed in biological triplicates, the four bicyclic peptides (PK407, PK408, PK411 and PK417) isolated without pancreatin pressure showed on average 68-fold and 159-fold increased $\mathrm{IC}_{50} \mathrm{~s}$ when treated for $30 \mathrm{~min}$ at $37^{\circ} \mathrm{C}$ with $10 \mu \mathrm{g} / \mathrm{ml}$ and $20 \mu \mathrm{g} / \mathrm{ml}$ pancreatin, respectively (Fig. 3A, Table I). In contrast, three of the five peptides isolated under pancreatin pressure (PK459, PK472 and PK474) presented significantly smaller losses in inhibitory activity when treated with 10 and $20 \mu \mathrm{g} / \mathrm{ml}$ pancreatin, their $\mathrm{IC}_{50} \mathrm{~s}$ increasing on average 2-, 2- and 3-fold and 7-, 6- and 15-fold, respectively (Fig. 3A, Table I). We next assessed by HPLC the protease resistance of the three bicyclic inhibitors having shown an improved stability in the inhibition assay (PK459, PK472 and PK474) versus three bicyclic inhibitors isolated without proteolytic pressure (PK407, PK408 and PK411). The percentage of non-digested peptide remaining after in vitro digestion with the various concentrations of pancreatin (10 and $20 \mu \mathrm{g} / \mathrm{ml}$ ) was determined by measuring the area under the peaks in the HPLC chromatograms (Fig. 3B). When treated with $20 \mu \mathrm{g} / \mathrm{ml}$ pancreatin, inhibitors selected without proteolytic pressure were almost completely digested (in average $<2 \%$ undigested inhibitor remaining) whereas the fractions of intact bicyclic peptide of the protease resistant group were in average 16, 20 and 9\%, respectively (Fig. 3C).

\section{Proline in position 5 increases proteolytic stability}

Sequence comparison of bicyclic peptides displaying a higher stability toward pancreatin revealed the presence of a proline residue in position 5 (PK459, PK472 and PK474), which is not found in all the bicyclic peptides that proved more prone to pancreatic digestion (PK407, PK408, PK411, PK417, PK456 and PK473; Fig. 2B). This observation suggested that the presence of a proline in this specific position might increase the proteolytic stability. To assess the potential finding of such a 'protective mark', three proteasesusceptible peptides (PK407, PK408 and PK411) were synthesized with a proline in position 5 (PK407-Pro, PK408-Pro and PK411-Pro; Fig. 4A). After cyclization, their resistance to proteolytic degradation was compared with the proline-free counterparts by measuring the $\mathrm{IC}_{50} \mathrm{~S}$ of all six bicyclic peptides pre- and post-in vitro digestion. As shown in Fig. 4A, the introduction of a proline in position 5 did not significantly affect the inhibitory activity pre-in vitro digestion. When treated with pancreatin, the bicyclic peptides with proline showed a much smaller reduction in inhibitory activity than their proline-free counterparts (Fig. 4B). The residual inhibitory activity following pancreatin treatment is compared for all the bicyclic peptides in Fig. 4C.

\section{Stability in intestinal fluid}

To gain an idea of the stability of the evolved bicyclic peptides in an intestinal environment, we incubated the most stable bicyclic peptide (PK411-Pro, $100 \mu \mathrm{g} / \mathrm{ml}$ ) in various dilutions of mouse intestinal fluid (MIF, isolated from the small intestine of 2-3 mice) and quantified the remaining fraction of intact inhibitor by HPLC. Incubation of PK411-Pro at $37^{\circ} \mathrm{C}$ for $30 \mathrm{~min}$ in 500-fold diluted MIF led to a similar extent of degradation as incubation with $20 \mu \mathrm{g} /$ $\mathrm{ml}$ pancreatin (between 35 and $40 \%$ of undigested bicyclic peptide) (Fig. 5, right panels). As expected, the bicyclic peptide PK411 without the proline residue was completely degraded at the same conditions (Fig. 5, left panels). The stability was much dependent on the concentration of bicyclic peptide in the assay. When the peptide was incubated at a 20 -fold higher concentration $(2 \mathrm{mg} / \mathrm{ml}), 10 \%$ of the bicyclic peptide PK411-Pro remained intact in 50-fold diluted MIF. Analysis by reversed-phase HPLC showed that the degradation products had similar retention times as those formed by pancreatin, suggesting similar enzymatic activities in the two extracts and that pancreatin is suitable to simulate the intestinal proteolytic activities.

\section{Discussion}

We have shown that bicyclic peptide antagonists with improved stability can be isolated from phage libraries by combined affinity and proteolytic selection. In a first set of experiments, we have assessed the stability of filamentous phage toward the pancreatic proteases found in the intestinal environment. While wild-type phage was completely stable toward high pancreatin concentrations, a mutant phage which we preferentially use for the screening of bicyclic peptide libraries was less resistant but stable enough to evolve bicyclic peptide inhibitors of hPK with improved stability compared 

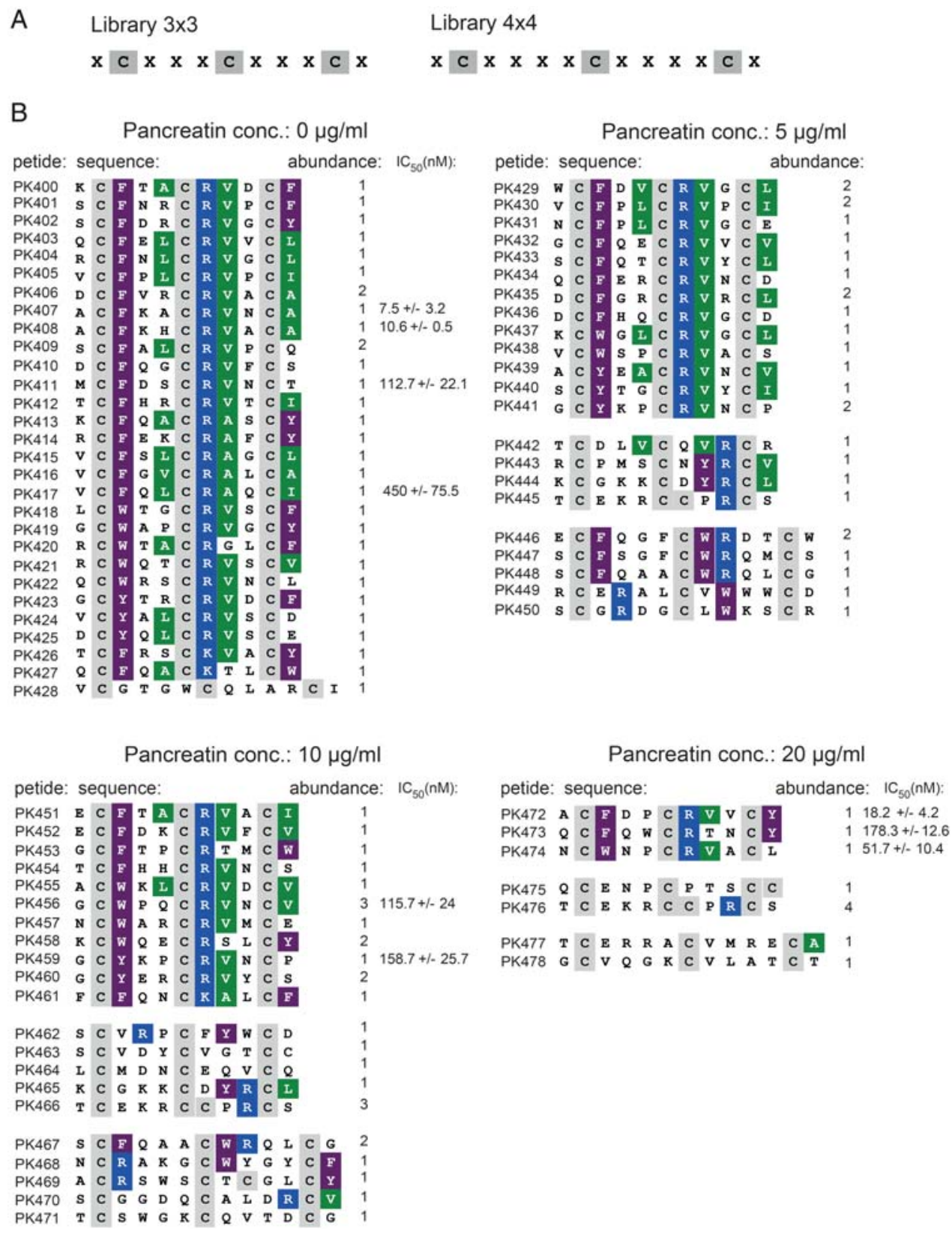

Fig. 2. Peptide library format and peptide sequences isolated with or without proteolytic pressure. (A) Format of phage peptide libraries $3 \times 3$ and $4 \times 4$. ' $X$ ' represents any of the 20 natural amino acids and ' $\mathrm{C}$ ' a cysteine residue. (B) Peptide sequences isolated after the second round of phage panning for the four different experimental conditions: $0 \mu \mathrm{g} / \mathrm{ml}$ (control), 5, 10 and $20 \mu \mathrm{g} / \mathrm{ml}$ pancreatin. Amino acid similarities are highlighted in color (Rasmol color code). Nine bicyclic peptides were chemically synthesized and their inhibitory activity $\left(\mathrm{IC}_{50}\right)$ is indicated.

with the previously developed inhibitor PK15. To improve further the stability of the bicyclic peptide hPK inhibitors, we estimate that the herein applied phage with disulfide-free p3 is not sufficiently resistant to proteases. However, it might be possible to improve the stability of the mutant phage toward intestinal proteases by directed evolution, similarly as Schmid and co-workers had improved the stability of filamentous phage to high temperatures and chymostrypsin (Martin and Schmid, 2003; Kather et al., 2005).

Three out of five bicyclic peptides isolated under proteolytic pressure were significantly more stable toward pancreatic proteases than all those selected without proteolytic pressure. For all bicyclic peptides, the residual inhibitory activity correlated well with the degree of degradation observed in the HPLC chromatograms. Only a small number of discrete degradation products were seen in the chromatograms indicating that the bicyclic peptides were cleaved at a few specific sites. Most likely the products are generated by trypsin and chymotrypsin which dominate the proteolytic activity in the intestine and cleave preferentially after lysine or arginine and large hydrophobic amino acids, respectively. In reversed-phase HPLC, all degradation products eluted at a more polar solvent which is expected as cleavage of a peptide loop generates new N-termini and hence additional charged groups. The bicyclic peptides with improved stability showed digestion products with similar retention times in 
Table I. $\mathrm{IC}_{50} \mathrm{~s}$ of bicyclic peptide plasma kallikrein inhibitors measured before and after incubation with pancreatin

\begin{tabular}{|c|c|c|c|c|}
\hline & & $\mathrm{IC}_{50}(\mathrm{nM})$ & & \\
\hline & & $\begin{array}{l}\text { No } \\
\text { pancreatin }\end{array}$ & $\begin{array}{l}10 \mu \mathrm{g} / \mathrm{ml} \\
\text { pancreatin }\end{array}$ & $\begin{array}{l}20 \mu \mathrm{g} / \mathrm{ml} \\
\text { pancreatin }\end{array}$ \\
\hline Isolated & PK407 & $7.5 \pm 3.2$ & $1117 \pm 407$ & $2283 \pm 226$ \\
\hline without & PK408 & $10.6 \pm 0.5$ & $720 \pm 80$ & $1583 \pm 486$ \\
\hline proteolytic & PK411 & $112.7 \pm 22.1$ & $1900 \pm 507$ & $15600 \pm 5973$ \\
\hline pressure & PK417 & $450 \pm 75.5$ & $17200 \pm 3020$ & $>20000$ \\
\hline Isolated with & PK456 & $115.7 \pm 24$ & $10193 \pm 3687$ & $>20000$ \\
\hline proteolytic & PK459 & $158.7 \pm 25.7$ & $347 \pm 98$ & $1120 \pm 250$ \\
\hline pressure & PK472 & $18.2 \pm 4.2$ & $39 \pm 3$ & $101 \pm 32$ \\
\hline & PK473 & $178.3 \pm 12.6$ & $11733 \pm 1617$ & $19600 \pm 693$ \\
\hline & PK474 & $51.7 \pm 10.4$ & $178 \pm 12$ & $793 \pm 78$ \\
\hline Rationally & PK407-Pro & $17.7 \pm 7.5$ & $48 \pm 14$ & $347 \pm 23$ \\
\hline designed & PK408-Pro & $27.3 \pm 9.5$ & $88 \pm 26$ & $390 \pm 61$ \\
\hline & PK411-Pro & $64 \pm 16.1$ & $96 \pm 14$ & $158 \pm 29$ \\
\hline
\end{tabular}

The assay was performed in biological triplicates. The average and standard deviation are indicated.

the HPLC chromatograms but the cleavage occurred at significantly higher pancreatin concentrations.

An interesting observation was that all the three bicyclic peptides with improved stability contained a proline residue in the same amino acid position. It is known that pancreatic proteases such as trypsin or chymotrypsin do not efficiently cleave Xaa-Pro amide bonds. This protection mechanism may apply for the bicyclic peptide PK459 in which the trypsin substrate lysine is followed by the proline but likely not for the other two biyclic peptides (PK472 and PK474). In these peptides, the proline may constrain the conformation of the first peptide loop (or indirectly the second one) through its locked $\phi$ dihedral angle. To confirm the role of proline as a 'protective mark', we introduced proline into three bicyclic peptides that showed low stability. The mutants indeed showed a higher stability wherein the improvement was in the same range as the one of the phage selected clones. Analysis of the cleavage sites in the bicyclic peptides might help understanding better the role of proline in stabilizing the macrocycles.

Finally, we assessed the stability of the most stable bicyclic peptide in intestinal fluid of mice which showed that at the lower concentration tested $(100 \mu \mathrm{g} / \mathrm{ml}), 36 \%$ of the bicyclic peptide resisted 500 -fold diluted intestinal fluid at $37^{\circ} \mathrm{C}$ for $30 \mathrm{~min}$. If applied at higher concentration $(2 \mathrm{mg} / \mathrm{ml})$, the bicyclic peptide was significantly more resistant, namely $10 \%$ resisted a 50 -fold diluted intestinal fluid. Therefore, a higher dosage of this potent inhibitor should significantly help increasing its oral bioavailability. The higher stability of the peptide macrocycle evolved in this work should allow the use of milder excipients such as lower concentrations of protease inhibitors, interfering less with the natural gastrointestinal activity.

In conclusion, we show that implementing pancreatic digestion pressure in phage affinity selections is an attractive avenue to enrich peptide macrocycles with higher stability in intestinal fluid. The approach allowed us to further improve the stability of already relatively stable bicyclic peptide inhibitors which is an important step toward the development of an orally available hPK antagonist.

\section{Material and methods}

\section{Cloning of phage libraries}

The library $3 \times 3$ was cloned as follows. The genes encoding semi-random peptides with the sequence Xaa-Cys-(Xaa) ${ }_{3}$-Cys$\left(\right.$ Xaa ${ }_{3}$-Cys-Xaa, the linker Ser-His-Ser and the two disulfidefree domains D1 and D2 were cloned in the correct orientation into the phage vector 21tet(5). The vector is based on the phage vector fdg3p0ss21 (Kather et al., 2005) and contains a $2.5 \mathrm{~kb}$ stuffer fragment instead of the gene region coding for the D1 and D2 domains of phage $\mathrm{p} 3$. The vector was cloned by ligating two SfiI-digested DNA fragments obtained in two separate polymerase chain reaction (PCR). In the first PCR reaction, nearly the whole vector fdg3p0ss21 (excluding the genes coding D1 and D2) was amplified with the primers $\mathrm{g} 3 \mathrm{pNba}$ (CAGTCAGGCCTCGGGGGCCATGGCTTCTGGTACCCCGGTTAAC) and pelbsfifo (GACTGAGGCCGGCTGGGCCGCATAGAAAGGAACAACTAAAGGAAT). In the second PCR reaction, the tetracycline resistance gene from the vector fd-tet-DOG1 (Hoogenboom et al., 1991) was amplified with the primers tetsfiba (CAGTCAGGCCCAGCCGGCCGATCTCGGGAAAAGCGTTGGTCAC) and tetsfifo (GACTGAGGCCCCCGAGGCCTTCCCTTTGTCAACAGCAATGG). The ligated DNA was transformed into TG1 cells. The genes encoding the peptide repertoire and the two $\mathrm{p} 3$ domains were created in a PCR reaction with the two primers sficx 3 ba (5'-TATGCGGCCCAGCCGGCCATGGCANNKTGTNNKNNKNNKTGCNNKNNKNNKTGTNNKTCTCACTCCGCTGAAACTGTTG-3' and sfi2fo (5'-CCATGGCCCCCGAGGCCGCGGCCGCATTGACAGG-3') using the vector fdg3p0ss 21 as a template. $11 \mu \mathrm{g}$ of SfiI-digested PCR product and $55 \mu \mathrm{g}$ SfiI-digested 21tet(5) vector were ligated and electroporated into TG1 cells. The transformed cells were incubated for $1 \mathrm{~h}$ in $2 \mathrm{YT}$ media at $37^{\circ} \mathrm{C}$ and plated on seven large $(20 \mathrm{~cm}$ diameter) chloramphenicol (30 $\mu \mathrm{g} / \mathrm{ml}) 2 \mathrm{YT}$ plates. Colonies were scraped off the plates with 2 YT media, supplemented with $10 \%$ glycerol and stored at $-80^{\circ} \mathrm{C}$. The library $4 \times 4$ was cloned as follows. The genes encoding semi-random peptides with the sequence Xaa-Cys-(Хaa) ${ }_{4}$-Cys-(Xaa) ${ }_{4}$-Cys-Xaa, the linker Ser-His-Ser and the two disulfide-free domains D1 and D2 were cloned in the correct orientation into the phage vector fd0ssD12 (Heinis et al., 2009). The genes encoding the peptide repertoire and the two $\mathrm{p} 3$ domains were created in a PCR reaction with the two primers sficx4ba (5'-TATGCGGCCCAGCCGGCCATGGCANNKTGTNNKNNKNNKNNKTGCNNKNNKNNKNNKTGTNNKTCTCACTCCGCTGAAACTGTTG- $3^{\prime}$ and sfi2fo (5'-CCATGGCCCCCGAGGCCGCGGCCGCATTGACAGG-3') using the vector fdg3p0ss21 as a template. $13.5 \mu \mathrm{g}$ of SfiI-digested PCR product and $67 \mu \mathrm{g}$ SfiI-digested fd0ssD12 vector were ligated and electroporated into TG1 cells. The transformed cells were incubated for $1 \mathrm{~h}$ in $2 \mathrm{YT}$ media at $37^{\circ} \mathrm{C}$ and plated on seven large $(20 \mathrm{~cm}$ diameter $)$ chloramphenicol $(30 \mu \mathrm{g} / \mathrm{ml})$ 2YT plates. Colonies were scraped off the plates with $2 \mathrm{YT}$ media, supplemented with $10 \%$ glycerol and stored at $-80^{\circ} \mathrm{C}$.

\section{Phage selections combined with in vitro digestion}

Glycerol stocks of phage libraries (library $3 \times 3$ and library $4 \times 4$ ) were each diluted to $\mathrm{OD}_{600}=0.1$ in $1.512 \mathrm{YT} / \mathrm{chlor}$ amphenicol $(30 \mu \mathrm{g} / \mathrm{ml})$ cultures and phage were expressed at $30^{\circ} \mathrm{C}$ overnight $(15-16 \mathrm{~h})$. Phage from both libraries were purified, chemically modified as described in Heinis et al. 
A
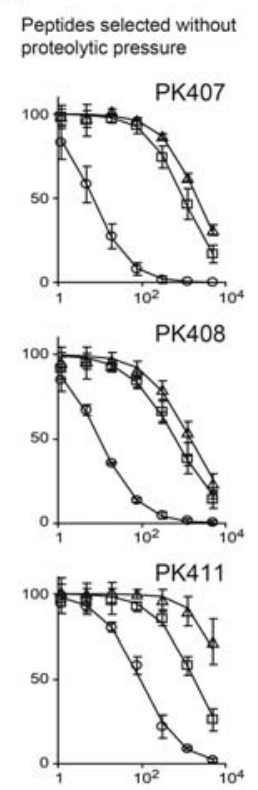

PK417

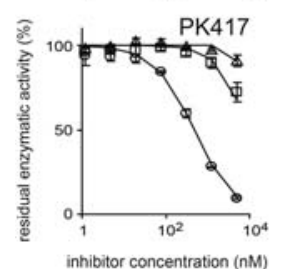

pancreatin conc:

O $0 \mu \mathrm{g} / \mathrm{ml}$

ㅁ $10 \mu \mathrm{g} / \mathrm{ml}$

$\Delta 20 \mu \mathrm{g} / \mathrm{ml}$

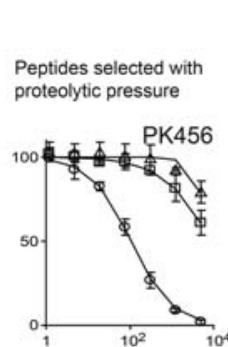

B

Peptides selected without proteolytic pressure
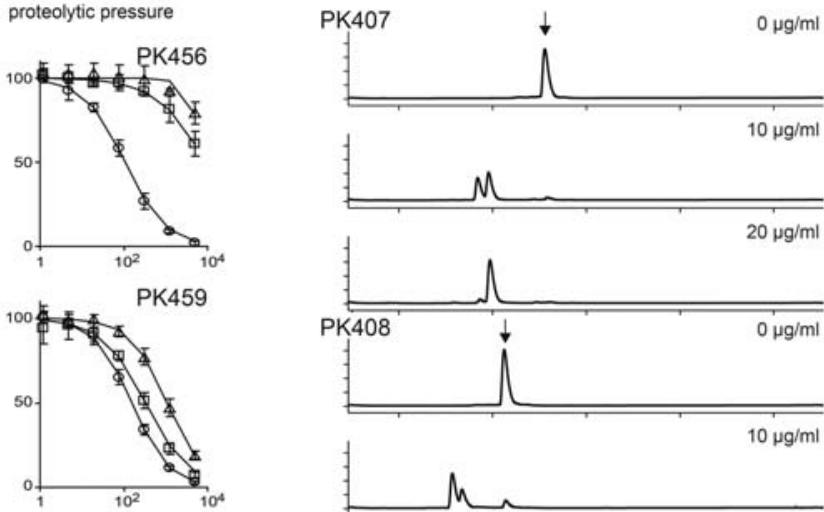

PK472

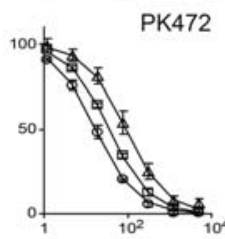

PK473

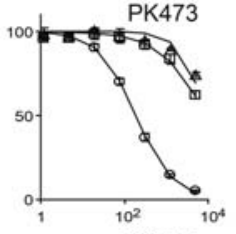

PK474

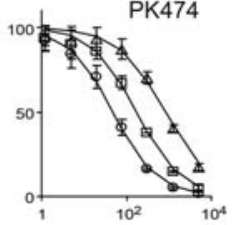

$20 \mu \mathrm{g} / \mathrm{ml}$

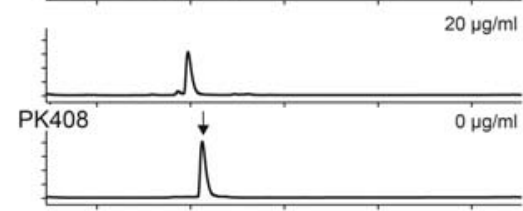

$10 \mu \mathrm{g} / \mathrm{m}$
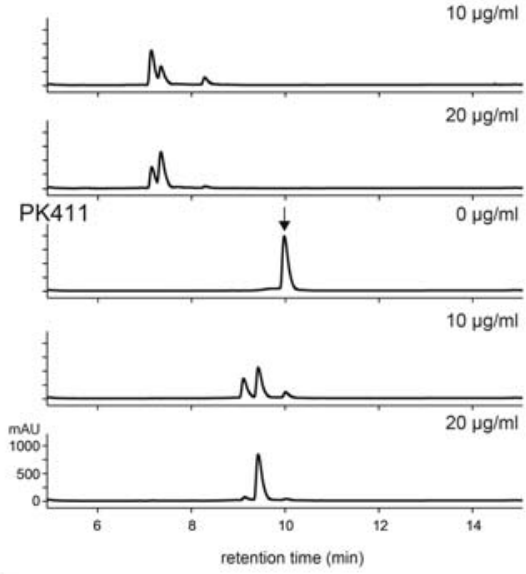

C

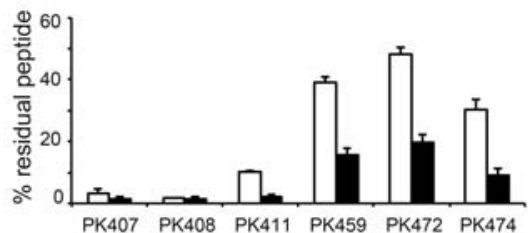

Peptides selected with proteolytic pressure

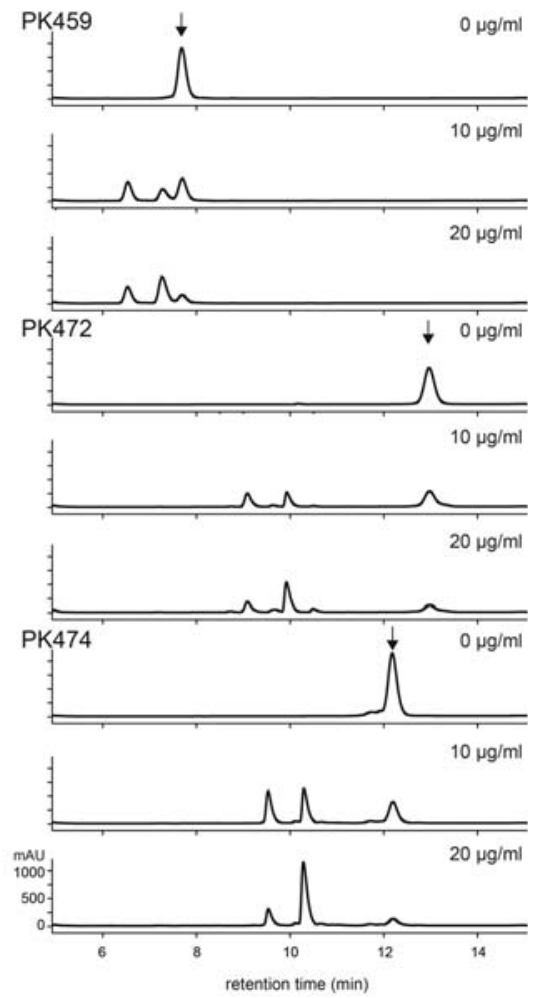

$\square 10 \mu \mathrm{g} / \mathrm{ml}$

Fig. 3. Proteolytic stability of selected bicyclic peptides. (A) Inhibitory activity pre- and post-in vitro digestion with 10 and $20 \mu \mathrm{g} / \mathrm{ml}$ pancreatin. In contrast to

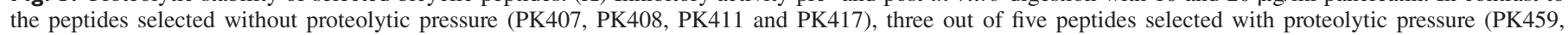

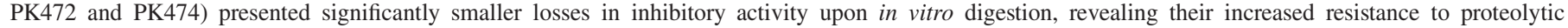

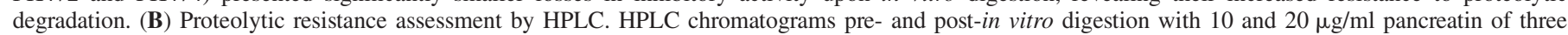

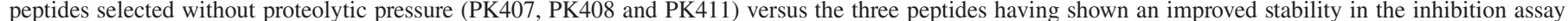

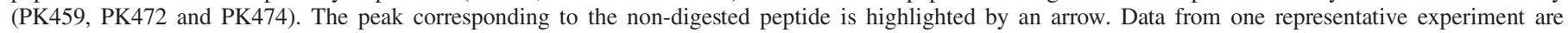

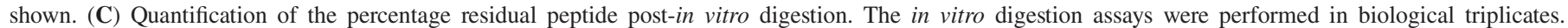
Medium values and the corresponding standard deviations are indicated.

(2009) and pooled in a $1: 1$ mixture. Biotinylated hPK ( $3 \mu \mathrm{g}$; Innovative Research, Novi, MI, USA) was incubated with $50 \mu \mathrm{l}$ pre-washed magnetic streptavidin beads (Dynal, M-280 from Life Technologies, Carlsbad, CA, USA) for $10 \mathrm{~min}$ at room temperature. Beads were washed three times prior to blocking with $0.5 \mathrm{ml}$ buffer A (10 mM Tris-Cl, $\mathrm{pH}$ 7.4, $150 \mathrm{mM} \mathrm{NaCl}, 10 \mathrm{mM} \mathrm{MgCl} 2,1 \mathrm{mM} \mathrm{CaCl}$ ) containing $1 \%$ bovine serum albumin (BSA) and $0.1 \%$ Tween 20 for $30 \mathrm{~min}$ at room temperature with rotation. Chemically modified phage (typically $10^{10}-10^{11}$ t.u. dissolved in $2 \mathrm{ml}$ buffer A) were concomitantly blocked by addition of $1 \mathrm{ml}$ buffer A containing $3 \%$ BSA and $0.3 \%$ Tween 20. Blocked bead conjugates were then mixed with the blocked phage and incubated for $30 \mathrm{~min}$ on a rotating wheel at room temperature. Beads were washed eight times with buffer A containing $0.1 \%$ Tween 20 and twice with buffer $\mathrm{A}$ before incubation with $100 \mu \mathrm{l}$ of $50 \mathrm{mM}$ glycine, $\mathrm{pH} 2.2$ for $5 \mathrm{~min}$. Eluted phage were transferred to $50 \mu \mathrm{l}$ of $1 \mathrm{M}$ Tris- $\mathrm{Cl}, \mathrm{pH} 8$ for neutralization, incubated with $30 \mathrm{ml}$ TG1 cells at
$\mathrm{OD}_{600}=0.4$ for $90 \mathrm{~min}$ at $37^{\circ} \mathrm{C}$ and the cells were plated on large 2YT/chloramphenicol plates. Bacteria were collected and cultured in $112 \mathrm{YT} / \mathrm{chloramphenicol}(30 \mu \mathrm{g} / \mathrm{ml})$ media for phage production as described above. After purification and chemical modification, the phage were incubated for $30 \mathrm{~min}$ at $37^{\circ} \mathrm{C}$ with four different pancreatin (Sigma Aldrich, St Louis, MO, USA) concentrations: $0 \mu \mathrm{g} / \mathrm{ml}$

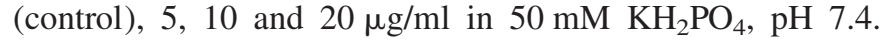
Buffer exchange was performed post-in vitro digestion $(3000 \times$ pancreatin dilution) by concentrating the reaction in a centrifugation filter (Vivaspin 20, 10 MWCO; Sartorius, Göttingen, Germany) and dilution with buffer A. A second round of panning was performed using the same selection procedures but neutravidin-coated magnetic beads to prevent the enrichment of streptavidin-specific peptides. The neutravidin beads were prepared by reacting $0.8 \mathrm{mg}$ neutravidin (Pierce, Rockford, IL, USA) with $0.5 \mathrm{ml}$ tosyl-activated magnetic beads (Dynal, M-280 from Life Technologies) according to the supplier's instructions. 
A

Peptide sequence:

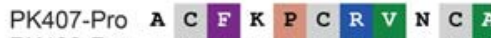

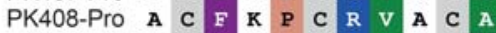

PK411-Pro M C $F$ D $P$ P C $R$ R V N

$\mathrm{IC}_{50}(\mathrm{nM})$

$17.7+1-7.5$

$27.3+1-9.5$

$64+/-16.1$

B
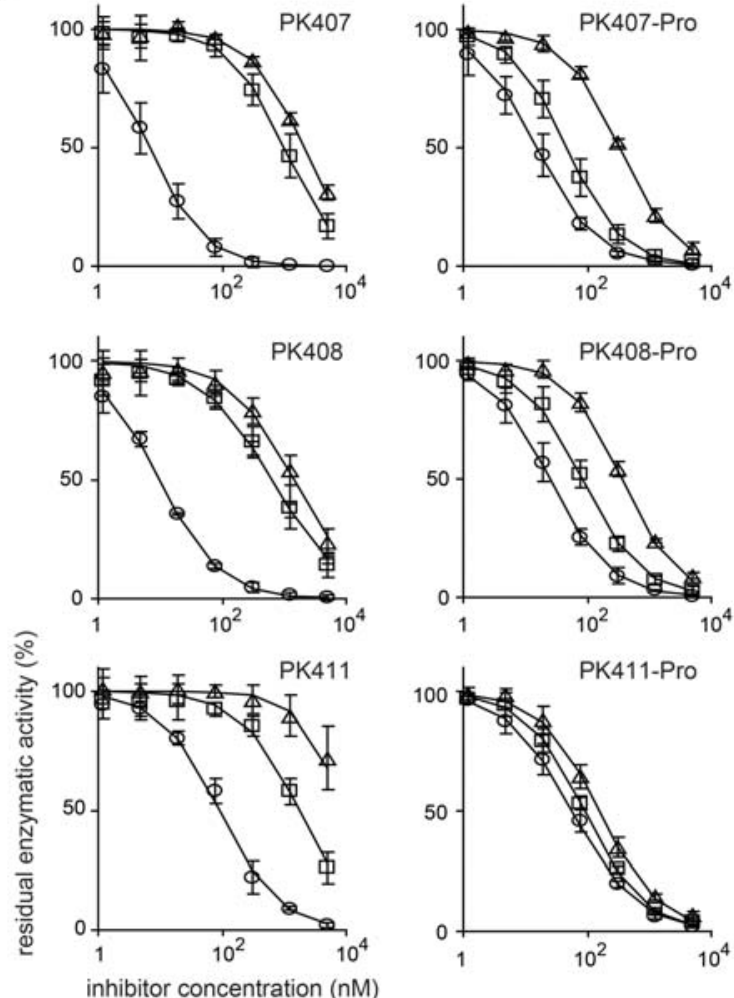

pancreatin conc.: $\quad \bigcirc 0 \mu \mathrm{g} / \mathrm{ml}$

$10 \mu \mathrm{g} / \mathrm{ml}$

$\Delta 20 \mu \mathrm{g} / \mathrm{ml}$

C
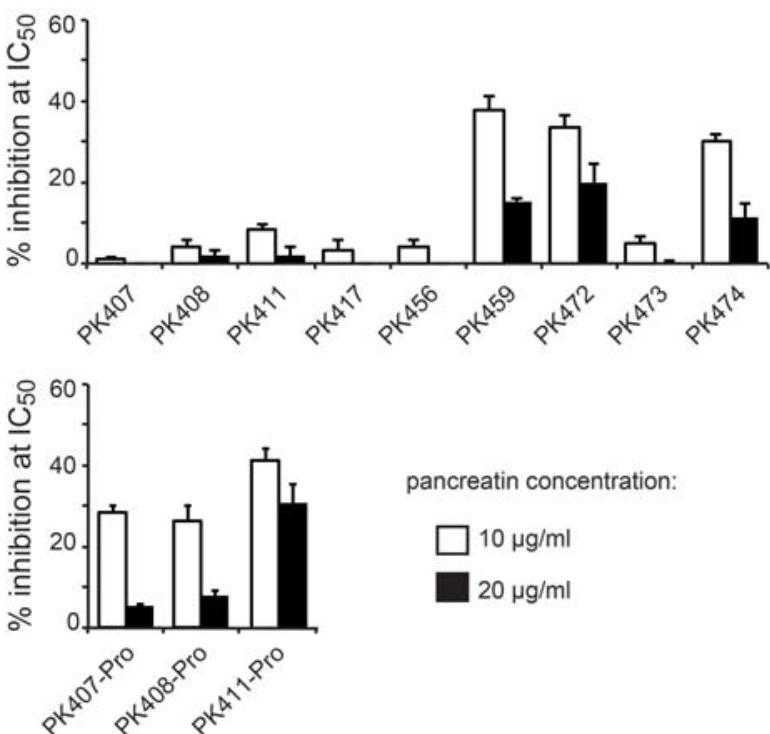

Fig. 4. Effect of proline in position 5 on the proteolytic stability. (A) Three bicyclic peptides without improved proteolytic stability (PK407, PK408 and PK411) were re-synthesized with a proline in position 5 and their $\mathrm{IC}_{50} \mathrm{~S}$ determined. (B) Inhibitory activities of PK407-Pro, PK408-Pro and PK411-Pro pre- and post-treatment with 10 or $20 \mu \mathrm{g} / \mathrm{ml}$ pancreatin. The bicyclic peptides with proline showed a substantially smaller reduction in inhibitory activity upon in vitro digestion compared with their proline-free counterparts, confirming the protective benefit of a proline in position 5 .

\section{Bicyclic peptide synthesis}

Fmoc-protected amino acids were purchased from Bachem (Bubendorf, Switzerland) or GL Biochem (Shanghai, China). Rink Amide AM resin (200-400 mesh, loading $0.36 \mathrm{mmol} / \mathrm{g}$ ), O-Benzotriazole- $N, N, N^{\prime}, N^{\prime}$-tetramethyl-uronium-hexafluorophosphate (HBTU) and $N$-ethyldiisopropylamine (DIEA) were purchased from Iris Biotech (Marktredwitz, Germany). Piperidine, trifluoroacetic acid (TFA) and 1,2-ethanedithiol (EDT) were used as received from Sigma Aldrich. Acetonitrile (ACN) was purchased from Thermo Fisher Scientific (Waltham, MA, USA). The peptides were prepared by solid-phase peptide synthesis on an Advanced ChemTech $348 \Omega$ peptide synthesizer (Aapptec, Louisville, USA), by standard 9-fluorenylmethoxycarbonyl (Fmoc) group chemistry protocols and Rink Amide AM resin support (0.1 mmol scale). Fmoc groups were removed using $2.5 \mathrm{ml}$ of a $20 \%(\mathrm{v} / \mathrm{v})$ solution of piperidine in dimethylformamide (DMF) and amino acid coupling was carried out following a double-coupling strategy with a 6-fold excess of Fmoc-amino acids (0.2 M in DMF). Coupling was achieved using a 1/0.9/2 ratio of amino acid/HBTU/DIEA in DMF. The deprotection and coupling times were 5 and $30 \mathrm{~min}$, respectively. Five times $3 \mathrm{ml}$ DMF washes were performed after deprotection and coupling steps. The peptide-loaded resin was treated with a 90/2.5/2.5/2.5/2.5 (v/v) mixture of TFA/thioanisole/water/phenol/EDT for $3 \mathrm{~h}$, which simultaneously cleaved the peptide from the resin and removed all side-chain protective groups. The cleaved peptides were subsequently isolated by precipitation in cold diethyl ether followed by centrifugation. The precipitated peptides were resuspended in diethyl ether and centrifuged (three times). Finally, the peptides were dissolved in a solution of $50: 50$ ACN: MilliQ water and lyophilized. The synthetic peptides

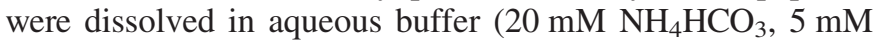
ethylenediaminetetra-acetate (EDTA), $\mathrm{pH}$ 8.0) at a concentration of $0.5 \mathrm{mM}$ and TBMB dissolved in $\mathrm{ACN}$ was added to obtain the following final concentrations: $80 \%$ aqueous buffer (20 $\mathrm{mM} \mathrm{NH}_{4} \mathrm{HCO}_{3}, 5 \mathrm{mM}$ EDTA, pH 8.0, degased), $20 \% \mathrm{ACN}, 0.5 \mathrm{mM}$ peptide and $1 \mathrm{mM}$ TBMB. The reaction solutions were kept in a $30^{\circ} \mathrm{C}$ water bath for $1 \mathrm{~h}$.

The product was purified by reversed-phase HPLC (XBridge BEH300 Prep C18 column; Waters, Milford, MA, USA) on a Waters Prep LC 4000 system with a $99.9 \% \mathrm{H}_{2} \mathrm{O} /$ $0.1 \%$ TFA:99.9\% ACN/0.1\% TFA linear gradient from 0 to $50 \%$ over $30 \mathrm{~min}$ at a flow rate of $6 \mathrm{ml} / \mathrm{min}$. The composition of the peptide was confirmed by electrospray ionization mass spectrometry (TSQ7000, Thermo Fisher Scientific). The purified peptides were freeze dried.

\section{In vitro digestion assay}

In vitro digestion assay using pancreatin: $10 \mu \mathrm{g}$ of peptide was incubated with different pancreatin concentrations $(0,10$ and $20 \mu \mathrm{g} / \mathrm{ml}$ ) in $100 \mu \mathrm{l}$ of $50 \mathrm{mM} \mathrm{KH}_{2} \mathrm{PO}_{4}, \mathrm{pH} 7.4$ for $30 \mathrm{~min}$ at $37^{\circ} \mathrm{C}$. Pancreatin was inactivated post-incubation

In vitro digestion assays were performed in biological triplicates. Medium values and the corresponding standard deviations are indicated. (C) Quantification of the residual inhibitory activity post-in vitro digestion. The extent of inhibition (\% enzymatic activity blocked) was measured at an inhibitor concentration equalling the $\mathrm{IC}_{50}$ of each bicyclic peptide. 


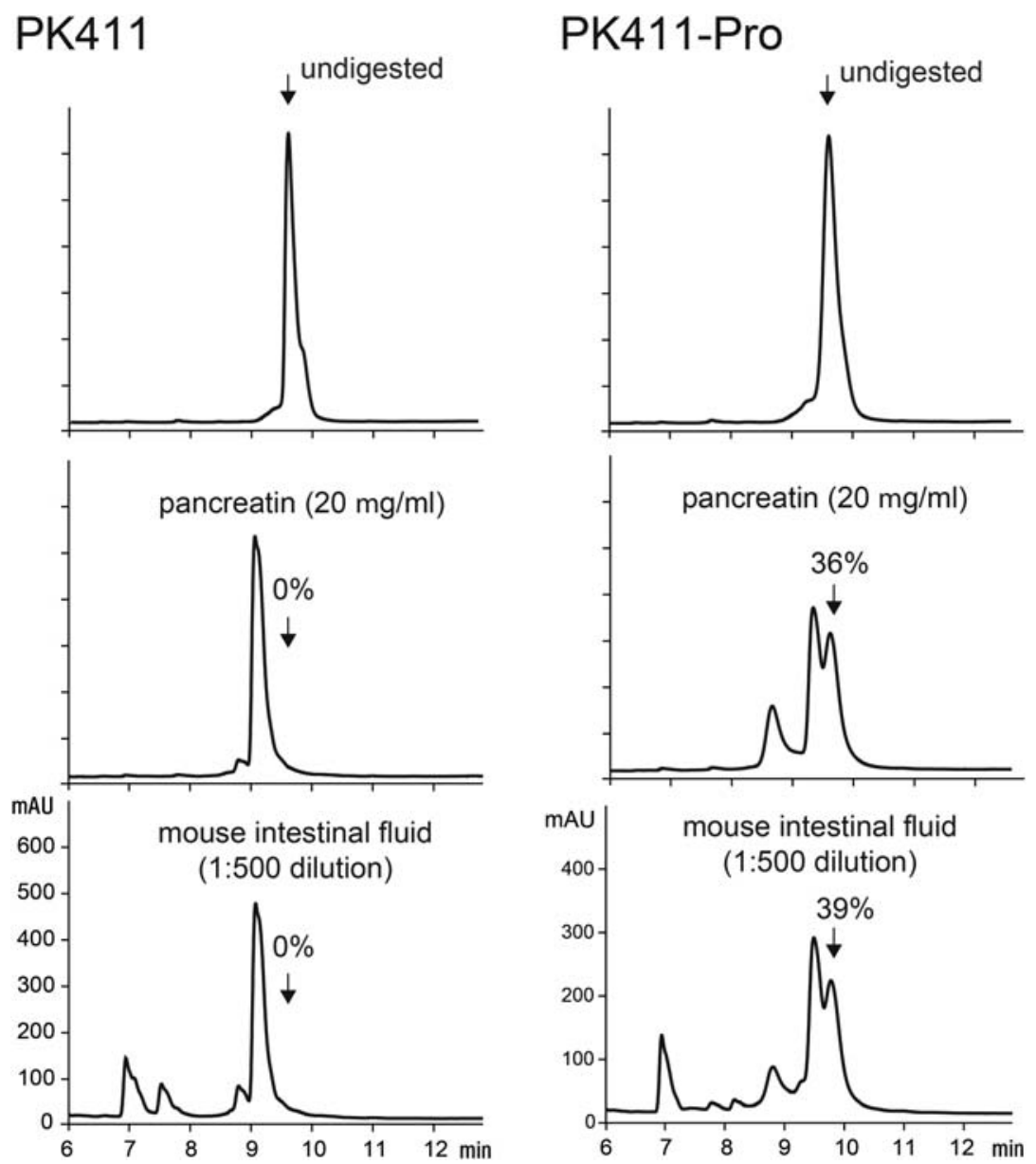

Fig. 5. Stability of PK411 and PK411-Pro in intestinal fluid. (A) HPLC chromatograms of bicyclic peptide (100 $\mu \mathrm{g} / \mathrm{ml})$ pre-in vitro digestion and post-in vitro digestion with either $20 \mu \mathrm{g} / \mathrm{ml}$ pancreatin or with a 500-fold dilution of MIF. The peak corresponding to the non-digested peptide is indicated by an arrow. The percentage residual peptide has been determined by measuring and comparing the area under the HPLC-derived peak corresponding to the non-digested peptide before and after in vitro digestion.

either by heat inactivation $\left(10 \mathrm{~min}\right.$ at $\left.100^{\circ} \mathrm{C}\right)$ or by acidic $\mathrm{pH}$ $(0.5 \%$ TFA). Assays were performed in biological triplicates.

In vitro digestion assay using mouse intestinal fluid: $100 \mu \mathrm{g}$ or $2 \mathrm{mg}$ of peptide were incubated for $30 \mathrm{~min}$ at $37^{\circ} \mathrm{C}$ with various dilution of mouse intestinal fluid. Enzymatic activity was stopped post-incubation by acidic $\mathrm{pH}$ $(0.5 \%$ TFA). Fresh mouse intestinal content was extracted from the small intestine of 2-3 mice, pooled and before use diluted with $50 \mathrm{mM} \mathrm{KH} \mathrm{PO}_{4}$, $\mathrm{pH} 7.4$.

\section{Inhibition assay}

Residual hPK activity was measured in buffer containing $10 \mathrm{mM}$ Tris-Cl, pH 7.4, $150 \mathrm{mM} \mathrm{NaCl}, 10 \mathrm{mM} \mathrm{MgCl}_{2}$, $1 \mathrm{mM} \mathrm{CaCl} 2,0.1 \%$ w/v BSA, $0.01 \%$ v/v Triton-X100 and $5 \% \mathrm{v} / \mathrm{v}$ dimethyl sulfoxide in a volume of $150 \mu \mathrm{l}$. Final concentration of hPK was $0.75 \mathrm{nM}$. Four-fold dilutions of inhibitors were prepared ranging from $20 \mu \mathrm{M}$ to $1.2 \mathrm{nM}$. For the determination of the $\mathrm{IC}_{50}$ inhibitory constants, the Z-Phe-Arg-AMC fluorogenic substrate (Bachem) was used at a final concentration of $50 \mu \mathrm{M}$. Fluorescence intensity was measured with a Spectramax Gemini fluorescence plate reader (excitation at $355 \mathrm{~nm}$, emission at $460 \mathrm{~nm}$; Molecular Devices, Sunnyvale, CA, USA). The reactions were performed at $25^{\circ} \mathrm{C}$. $\mathrm{IC}_{50}$ values were determined using the
Softmax Pro 3.1 software. Fitting curves were generated using Matlab software (MathWorks, Natick, MA, USA).

\section{HPLC}

Pre- and post-in vitro digestion samples were analyzed by reversed-phase HPLC (Zorbax, analytical C18 column; Agilent Technologies, Santa Clara, CA, USA) on an Agilent Technologies LC 1260 system with a $94.9 \% \mathrm{H}_{2} \mathrm{O} / 5 \%$ ACN/ 0.1\% TFA: $95 \%$ ACN $/ 4.9 \% \mathrm{H}_{2} \mathrm{O} / 0.1 \%$ TFA linear gradient from 0 to $100 \%$ over $20 \mathrm{~min}$ at a flow rate of $1 \mathrm{ml} / \mathrm{min}$. Peaks were integrated using the Agilent ChemStation software. The percentage of non-digested peptide remaining post-in vitro digestion was assessed by comparing the area under the corresponding peak pre- and post-in vitro digestion.

\section{Supplementary data}

Supplementary data are available at PEDS online.

\section{Acknowledgements}

We thank Sir Greg Winter for ideas, expert advice and feedback as well as Florian Formica and Dr Fabio Spiga for their precious technical help. 


\section{Funding}

The financial contribution from the Swiss National Science Foundation (SNSF Professorship PP00P3_123524/1 to C.H.) and the Novartis Foundation, formerly Ciba-Geigy Jubilee Foundation (post-doc fellowship to V.B.) is gratefully acknowledged.

\section{References}

Antosova,Z., Mackova,M., Kral,V. and Macek,T. (2009) Trends Biotechnol, 27, 628-635.

Baeriswyl,V., Rapley,H., Pollaro,L., Stace,C., Teufel,D., Walker,E., Chen,S., Winter,G., Tite,J. and Heinis,C. (2012) ChemMedChem, 7, 1173-1176.

Chakravarty,S., Mitra,N., Queitsch,I., Surolia,A., Varadarajan,R. and Dubel,S. (2000) FEBS Lett, 476, 296-300.

Finucane,M.D., Tuna,M., Lees,J.H. and Woolfson,D.N. (1999) Biochemistry, 38, 11604-11612.

Fischer,N., Riechmann,L. and Winter,G. (2004) Protein Eng Des Sel, 17, $13-20$.

Getz,J.A., Rice,J.J. and Daugherty,P.S. (2011) ACS Chem Biol, 6, 837-844.

Heinis,C., Rutherford,T., Freund,S. and Winter,G. (2009) Nat Chem Biol, 5, $502-507$.

Hoogenboom,H.R., Griffiths,A.D., Johnson,K.S., Chiswell,D.J., Hudson,P. and Winter,G. (1991) Nucleic Acids Res, 19, 4133-4137.

Kather,I., Bippes,C.A. and Schmid,F.X. (2005) J Mol Biol, 354, 666-678.

Kipnes,M., Dandona,P., Tripathy,D., Still,J.G. and Kosutic,G. (2003) Diabetes Care, 26, 421-426.

Kristensen,P. and Winter,G. (1998) Fold Des, 3, 321-328.

Laskowski,M. and Qasim,M.A. (2000) Biochim Biophys Acta, 1477, 324-337.

Mahato,R.I., Narang,A.S., Thoma,L. and Miller,D.D. (2003) Crit Rev Ther Drug Carrier Syst, 20, 153-214.

Martin,A. and Schmid,F.X. (2003) J Mol Biol, 328, 863-875.

Morishita,M., Goto,T., Nakamura,K., Lowman,A.M., Takayama,K. and Peppas,N.A. (2006) J Control Release, 110, 587-594.

Morishita,M. and Peppas,N.A. (2006) Drug Discov Today, 11, 905-910.

Pedersen,J.S., Otzen,D.E. and Kristensen,P. (2002) J Mol Biol, 323, $115-123$.

Riechmann,L. and Winter,G. (2006) J Mol Biol, 363, 460-468.

Riechmann,L. and Winter,G. (2000) Proc Natl Acad Sci U S A, 97, 10068-10073.

Sieber,V., Pluckthun,A. and Schmid,F.X. (1998) Nat Biotechnol, 16, 955-960.

Stolz,L.E. and Horn,P.T. (2010) Drugs Today (Barc), 46, 547-555.

Zhou,X.H. and Li Wan Po,A. (1991) International Journal of Pharmaceutics, 75, 117-130. 